\title{
(2) OPEN ACCESS \\ Milky pleural effusion in a neonate and approach to investigating chylothorax
}

\author{
Udara Dilrukshi Senarathne (1) , ${ }^{1,2}$ Ranmali Rodrigo, ${ }^{3}$ \\ Bolonghoge Krishantha Trixy Priyankara Dayanath ${ }^{2}$
}

${ }^{1}$ Department of Biochemistry, Faculty of Medical

Sciences, University of Sri Jayewardenepura, Nugegoda, Sri Lanka

${ }^{2}$ Department of Chemical Pathology, Colombo North Teaching Hospital, Ragama, Sri Lanka

${ }^{3}$ Department of Paediatrics, Faculty of Medicine, University of Kelaniya, Ragama, Sri Lanka

\section{Correspondence to}

Dr Udara Dilrukshi Senarathne; udara.senarathne@sjp.ac.lk

RR and BKTPD contributed equally.

Accepted 29 August 2021

Check for updates

(c) BMJ Publishing Group Limited 2021. Re-use permitted under CC BY-NC. No commercial re-use. See rights and permissions. Published by BMJ.

To cite: Senarathne UD, Rodrigo R, Dayanath BKTP. BMJ Case Rep

2021:14:e245576.

doi:10.1136/bcr-2021

245576

\section{SUMMARY}

Neonatal chylothorax is a rare presentation leading to significant respiratory distress, thus requiring timely diagnosis. A preterm neonate was resuscitated and ventilated, following which she clinically improved but subsequently developed respiratory distress with a right-sided pleural effusion. Interestingly, thoracentesis fluid appeared 'milky' with elevated triglycerides and lymphocytes, suggesting chylothorax. As fluid triglyceride level was lower than the established diagnostic criterion for chylothorax (1.24 mmol/L), a high fluid-to-serum triglyceride ratio was used as a surrogate diagnostic marker, later confirmed by lipoprotein electrophoresis. As observed in the index patient, a critically ill neonate would have a lower-than-average fat intake leading to less chylomicron production, thus lower triglyceride levels in chyle than expected, which may still fail to meet the amended cut-off limit. This case highlights the challenges in diagnosing neonatal chylothorax due to the lack of age-specific triglyceride levels in chyle and low oral fat intake in critically ill patients.

\section{BACKGROUND}

Chylothorax is a rare cause of pleural effusion due to the extravasation of chyle from the thoracic duct or its tributaries. Neonatal chylothorax has an incidence of 1 in 5775 to 1 in 100000 live births but can be considered the most common form of pleural effusion encountered in the perinatal period. ${ }^{1-5}$ The diagnosis of chylothorax is based on the demonstration of chylomicrons through elevated triglyceride levels in the pleural fluid above the established cutoff limit of $1.24 \mathrm{mmol} / \mathrm{L}(110 \mathrm{mg} / \mathrm{dL})$ and elevated lymphocytes ( $>1000$ cells $/ \mu \mathrm{L}$ ) on the fluid microscopy. ${ }^{6-8}$ However, the absence of age-specific cutoff limits for triglyceride levels in the chyle and dependence of chyle triglyceride on oral fat intake pose a challenge in diagnosing chylothorax in neonates, as observed in the preterm neonate with a milky pleural effusion reported by us.

\section{CASE PRESENTATION}

A female infant was born at 25 weeks of gestation, with a birth weight of $665 \mathrm{~g}$ by vaginal breech delivery to a 36-year-old mother of one child. The mother had pregnancy-induced hypertension (treated with nifedipine), and received appropriate antenatal steroids. She went into preterm labour at the onset of which the cervical cerclage was removed, giving birth to an infant who was floppy at birth, with no spontaneous breathing but with a heart rate $>100 /$ min (Apgar score: $6^{1}, 8^{5}, 9^{10}$ ).
The infant was intubated shortly after birth due to increased work of breathing and subsequently received two doses of surfactant. Her chest X-ray on day 1 showed evidence of surfactant deficiency but no pleural effusion (figure 1A). She was not dysmorphic, and the remainder of her physical examination was normal.

The baby was started on trophic feeds with expressed breast milk (EBM) on day 2, and gradually increased to full feeds by day 5. Parenteral nutrition was not used due to the unavailability of custom preparations required to manage the infant's hyperglycaemia in the first few days. The infant had a late onset of Coliform sepsis from day 3 but remained stable respiratory-wise on conventional ventilation with a minimal increase in baseline oxygen requirement. However, over days 9 and 10, there was a deterioration in the respiratory status, with reduced air entry noted on the right side. On day 10 , a right-sided pleural effusion was confirmed on chest X-ray (figure 1B), and a thoracentesis was performed for therapeutic and diagnostic purposes due to the significant respiratory distress caused by the effusion. Interestingly, $14 \mathrm{~mL}$ of 'milky white' fluid (figure 2A) was drained, subsequently correcting the desaturations along with radiological improvement (figure 1C). A tentative diagnosis of right-sided chylothorax was made based on clinical and radiological findings supported by the elevated fluid-to-serum triglyceride ratio, elevated fluid triglyceride-to-cholesterol ratio and lymphocytosis in the pleural fluid. The baby was kept nil-bymouth, omitting EBM, and intravenous fluids were started. In addition, an intercostal tube was placed on the right side.

\section{INVESTIGATIONS}

The initial investigations revealed compensated respiratory acidosis, anaemia and hyperbilirubinaemia, and the infant later developed increased serum creatinine, thrombocytopenia and persistent hyperglycaemia with elevated inflammatory markers (table 1). The blood culture at birth was sterile.

Due to nasogastric feeding of EBM and the 'milky' nature of the pleural fluid, possible extravasation of breast milk from a perforated oesophagus was considered as one of the differential diagnoses prior to the aspirate being confirmed as chyle. The biochemical analysis of pleural fluid using EBM as the positive control showed that the EBM was strongly positive (figure 2B) for Benedict's test owing to its high lactose level; in contrast, pleural 


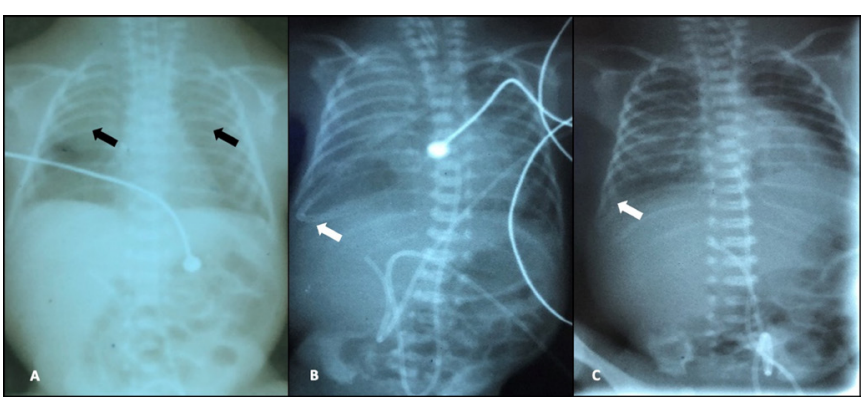

Figure 1 (A) Chest X-ray soon after birth showing ground-glass appearance with air bronchogram on bilateral lung fields. (B) Chest Xray on day 10 with obliteration of the right-sided costophrenic angle. (C) Chest X-ray following thoracentesis indicating resolution of right-sided pleural effusion.

fluid had only trace amounts of reducing substances (figure 2C). This observation excluded the possibility that the 'milky' pleural effusion was extravasated EBM. The biochemical analysis of thoracentesis fluid revealed elevated fluid triglyceride of $0.64 \mathrm{mmol} / \mathrm{L}$ (table 2), with a field full of lymphocytes on microscopy (figure 3), suggestive of chylothorax. Moreover, the fluid-to-serum triglyceride ratio was 1.9, with an elevated fluid triglyceride-to-cholesterol ratio indicating the chylous nature of the fluid.

Because the fluid triglyceride level failed to meet the established criterion for the diagnosis $(1.24 \mathrm{mmol} / \mathrm{L})$, we decided to conduct the gold standard lipoprotein electrophoresis to confirm the diagnosis of chylothorax. The pleural fluid was prestained with Sudan black and subjected to lipoprotein electrophoresis, which demonstrated no electrophoretic mobility (figure 4), confirming the presence of chylomicrons in the thoracentesis fluid. Thus, the diagnosis of right-sided chylothorax was confirmed, although an underlying cause for the chylothorax could not be ascertained definitively; birth trauma due to vaginal breech delivery was a probability.

\section{DIFFERENTIAL DIAGNOSIS}

The finding of a 'milky' pleural fluid in a neonate could be due to chylothorax, empyema, leakage of lipid in parenteral nutrition fluid from a central line or extravasated milk from a perforated oesophagus. The biochemical and microscopic analysis of thoracentesis fluid excluded empyema and milk extravasation into the pleural cavity. Although pseudo-chylothorax is a principal differential diagnosis under 'milky' effusions, it was considered unlikely in this patient due to the acute nature of the

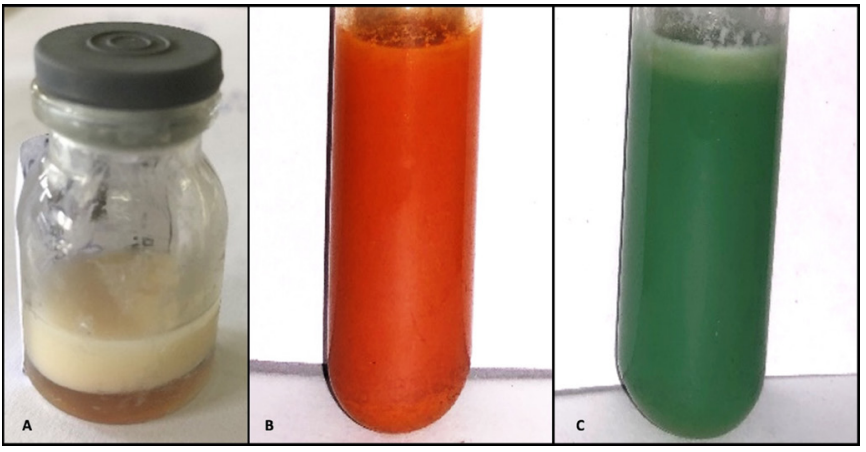

Figure 2 (A) Thoracentesis fluid, (B) strongly positive Benedict's test on expressed breast milk, $(C)$ weakly positive Benedict's test on thoracentesis fluid. presentation, and it was further excluded by the low cholesterol levels observed in the pleural fluid.

Possible causes for chylothorax in a neonate could be congenital or acquired in nature. However, congenital pathologies were considered less likely in this patient due to the prolonged latency of 10 days before developing the chylothorax and the absence of dysmorphism and other anomalies. In addition, chromosomal disorders associated with chylothorax-Down and Turner syndromes-were excluded by karyotyping. Therefore, perinatal trauma due to vaginal breech delivery, resulting in damage to the thoracic duct with the accumulation of chyle once enteral feeds were established, was considered the most plausible cause of chylothorax in the index patient, based on the clinical presentation.

\section{TREATMENT}

The respiratory distress of the neonate was managed as mentioned above, while umbilical venous and arterial accesses were obtained soon after birth. Empirical antibiotic treatment with benzylpenicillin and gentamicin was started from day 1 of life, where as meropenem, flucloxacillin, and sulbactam were added based on the antibiotic sensitivity of the blood cultures. The neonate required inotropic support with dobutamine over the first 2 days. Her initial haemoglobin was $76 \mathrm{~g} / \mathrm{L}$ (no antepartum haemorrhages and the infant's cranial ultrasound scan was normal), for which packed red cells were administered (posttransfusion $\mathrm{Hb} 189 \mathrm{~g} / \mathrm{L})$, while thrombocytopenia $\left(67 \times 10^{9} / \mathrm{L}\right)$ was managed with platelet transfusions. The Coomb's negative neonatal jaundice was managed with phototherapy. A summary of the investigation findings with the antibiotic treatment is given in table 3 .

Table 1 Summary of investigation results within the first 48 hours of life

\begin{tabular}{llll}
\hline Parameter & & Value & $\begin{array}{l}\text { Reference } \\
\text { limits }\end{array}$ \\
\hline Haematological & Haemoglobin & $76 \mathrm{~g} / \mathrm{L}$ & $140-240$ \\
parameters & White blood cells & $27.28 \times 10^{9} / \mathrm{L}$ & $3.1-21.6$ \\
& Neutrophils & $68 \%$ & $15-78$ \\
& Lymphocytes & $27 \%$ & $15-75$ \\
& Platelets & $220 \times 10^{9} / \mathrm{L}$ & $152-472$ \\
\hline Liver parameters & Aspartate transaminase & $68 \mathrm{U} / \mathrm{L}$ & $<35$ \\
& Alanine transaminase & $18 \mathrm{U} / \mathrm{L}$ & $<35$ \\
& Total bilirubin & $221 \mu \mathrm{mol} / \mathrm{L}$ & $<205$ \\
& Albumin & $21 \mathrm{~g} / \mathrm{L}$ & $28-42$ \\
Electrolytes and & Globulin & $11 \mathrm{~g} / \mathrm{L}$ & $18-28$ \\
renal parameters & Sodium & $131 \mu \mathrm{mol} / \mathrm{L}$ & $27-88$ \\
& Potassium & $138 \mathrm{mmol} / \mathrm{L}$ & $130-145$ \\
Acid-base balance & pH & $5.2 \mathrm{mmol} / \mathrm{L}$ & $3-6$ \\
and metabolic & pCO & 7.328 & $7.35-7.45$ \\
parameters & Bicarbonate & $47.2 \mathrm{~mm} \mathrm{Hg}$ & $35-45$ \\
& Base excess & $24.9 \mathrm{mmol} / \mathrm{L}$ & $22-26$ \\
& Lactate & $-2.4 \mathrm{mmol} / \mathrm{L}$ & $(-2)-(+2)$ \\
& Capillary blood glucose & $2.50 \mathrm{mmol} / \mathrm{L}$ & $0.5-2.22$ \\
& $11.6 \mathrm{mmol} / \mathrm{L}$ & $7.8-11.1$ \\
\hline Markers of infection & C-reactive protein & $7.48 \mathrm{mg} / \mathrm{dL}$ & $<5$ \\
& Peripheral blood smear & Toxic changes in neutrophils \\
& Blood culture & No growth & \\
\hline
\end{tabular}

Senarathne UD, et al. BMJ Case Rep 2021;14:e245576. doi:10.1136/bcr-2021-245576 
Table 2 Comparison of physical-chemical and microscopic findings of thoracentesis fluid, expressed breast milk and serum

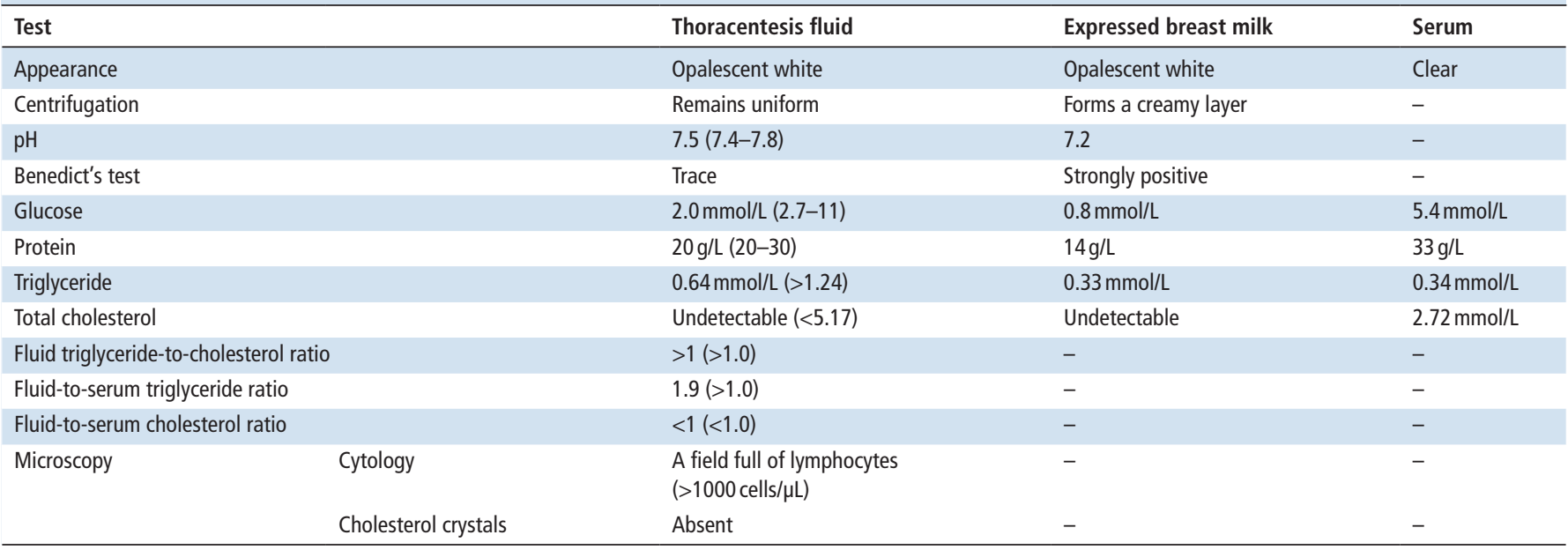

Reference limits for chyle are given within parentheses with the respective parameters. ${ }^{6-8}$

\section{OUTCOME AND FOLLOW-UP}

The respiratory distress was relieved following thoracentesis and parenteral nutrition with keeping the baby nil-by-mouth. However, the baby expired 2 days later due to overwhelming sepsis.

\section{DISCUSSION}

Chyle is a non-inflammatory, alkaline, bacteriostatic fluid composed of immunoglobulins, lymphocytes and dietary lipids. ${ }^{6-8}$ The thoracic duct transports a comparatively large volume of chyle daily, resulting in a rapid, significant accumulation of fluid within the pleural cavity in case of disruption to the flow. ${ }^{9}$ The lymphatics from the lower half of the body converge behind the aorta to form the thoracic duct, which runs on the right side of the vertebral column, locating the largest part of the thoracic duct within the right hemithorax, explaining the reason for chylothorax being frequently right sided. During the natural course of chylothorax, a chyloma (collection of chyle below the pleura) develops, which eventually bursts through the pleura to accumulate within the pleural space. ${ }^{6}$ Clinical manifestations of chylothorax depend on the rate of chyle leakage and the duration of chylothorax. Rapid considerable chyle accumulation can lead to significant cardiorespiratory morbidity by creating a positive pressure within the pleural cavity, as observed in the index patient. When long-standing, due to chronic loss of lymphocytes and immunoglobulins, chylothorax can lead to immunodeficiency, while chronic loss of fat and fat-soluble vitamins leads to

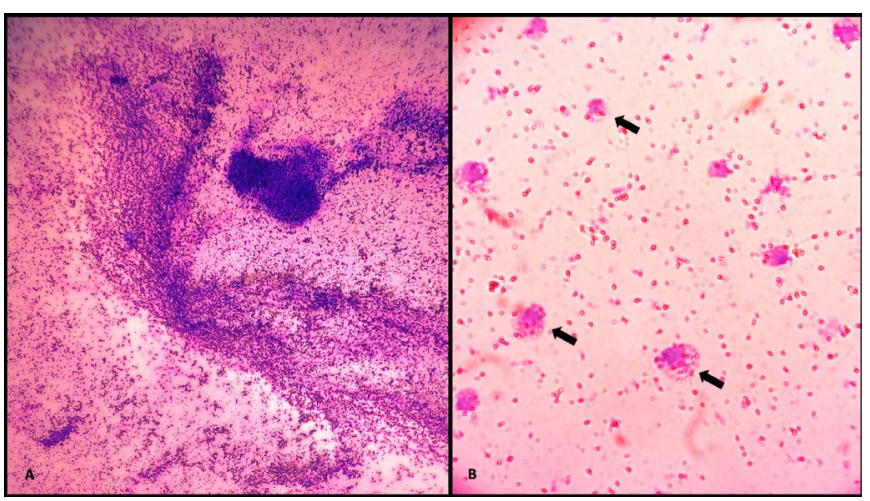

Figure 3 Field full of lymphocytes on pleural fluid microscopy. malnutrition. ${ }^{6}$ However, infections rarely occur in the extravasated chyle due to its bacteriostatic nature.

The diagnosis of chylothorax is based on the demonstration of chylomicrons and lymphocytes in the pleural fluid. The presence of chylomicrons can be confirmed by the elevated fluid triglyceride levels above the established cut-off limit of $1.24 \mathrm{mmol} / \mathrm{L}(110 \mathrm{mg} / \mathrm{dL})$ or by the gold standard lipoprotein electrophoresis. ${ }^{6-8}$ Fluid triglyceride levels $<0.56 \mathrm{mmol} / \mathrm{L}$ typically exclude chylothorax. ${ }^{10}$ Therefore, lipoprotein electrophoresis is essential, especially when the triglyceride levels are inconclusive $(0.56-1.24 \mathrm{mmol} / \mathrm{L}$ or $50-110 \mathrm{mg} / \mathrm{dL})$, as observed

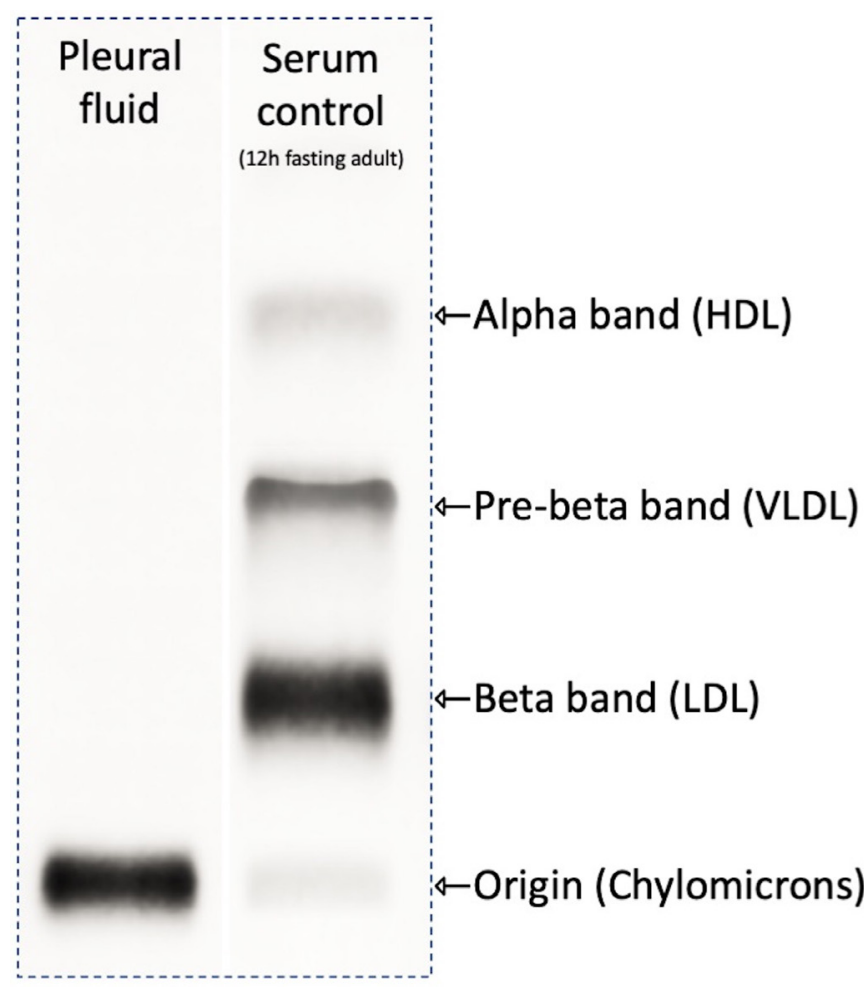

Figure 4 Lipoprotein electrophoresis of the pleural fluid vs lipoprotien electrophoresis of serum of a fasting adult (HDL: High density lipoprotein, VLDL: Very low density lipoprotein, LDL: Low density lipoprotein). 
Table 3 Summary of the investigation findings and antibiotic therapy with the timeline

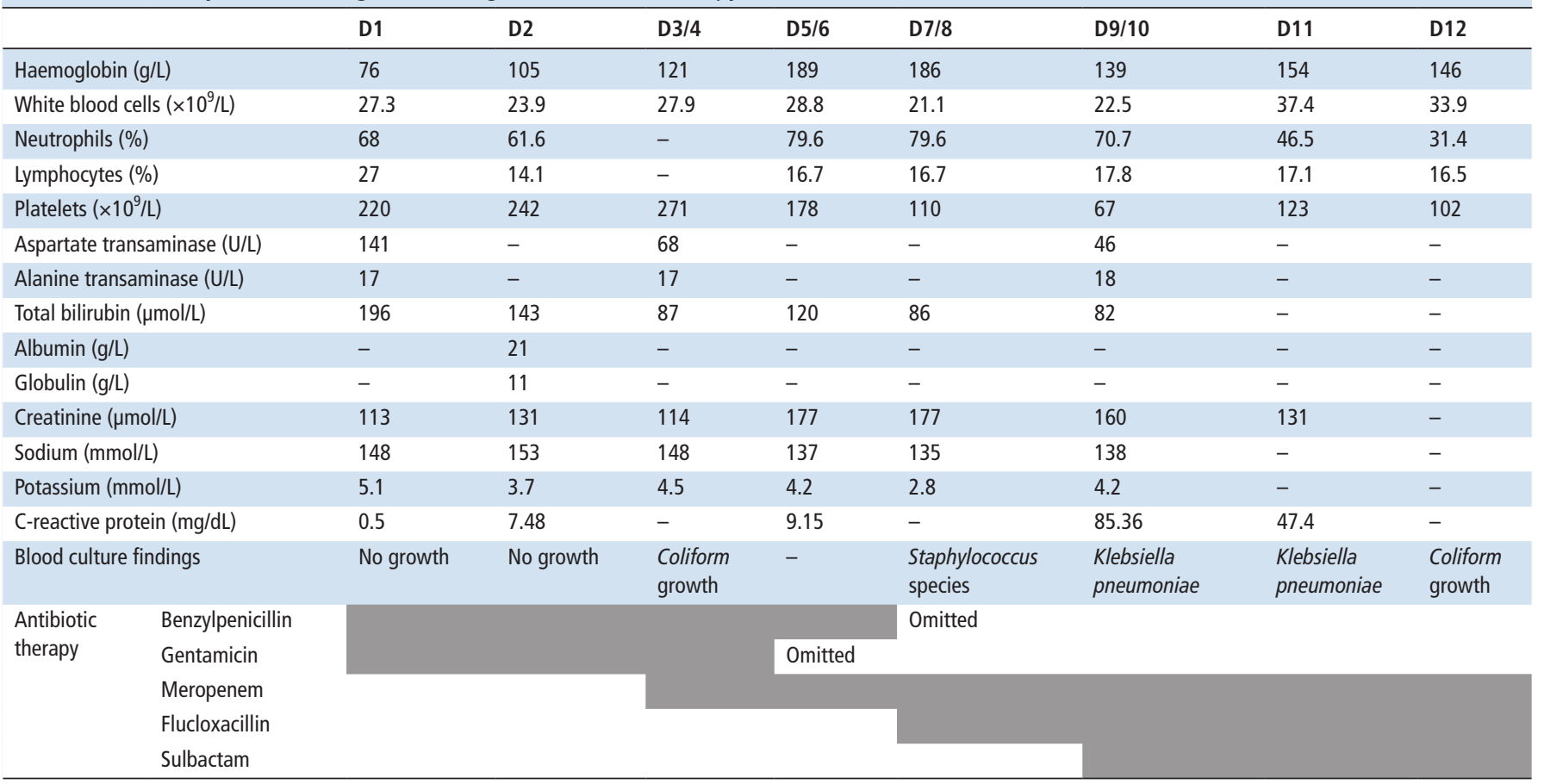

Coloured cells indicate the dates on which each antibiotic was given.

in this patient. ${ }^{711}$ Identification of chylomicrons by lipoprotein electrophoresis is based on the separation of lipoprotein particles according to their charge and mass under an electrical field. Due to the low protein content, chylomicrons are uncharged and remain at the origin (point of application), while any other lipoproteins present will demonstrate electrophoretic mobility.

Diagnosing chylothorax in neonates and children poses a challenge due to the absence of a clear definition of chyle triglyceride level, especially if the infant is not on full enteral feeds, as may be the case in neonates. Adult values are often applied due to the lack of evidence, although they may not necessarily represent paediatric biochemistry. van Straaten et al and Büttiker et al suggested using a lower triglyceride limit $(1.1 \mathrm{mmol} / \mathrm{L})$ for chyle in the paediatric patients. ${ }^{8} 12$ In their study on paediatric chylothorax, Büttiker et al provided an amended definition to its diagnosis as pleural fluid triglyceride $>1.1 \mathrm{mmol} / \mathrm{L}$ and an absolute cell count $>1000$ cells/ $\mu \mathrm{L}$ with a lymphocyte fraction $>80 \%$ which other researchers had later applied. ${ }^{8}$ They further emphasised the need for a mandatory minimal oral fat intake to diagnose chylothorax, especially in newborn infants, as the distinction between chylous and non-chylous effusion becomes difficult without oral fat intake. ${ }^{8}$ However, food consumption and malnutrition being confounding factors with considerable variability, lowering the cut-off limit may not necessarily alleviate the diagnostic confusion. Maldonado et al noted that $14 \%$ of chylomicron positive pleural effusions had triglyceride levels $<1.24 \mathrm{mmol} / \mathrm{L}$ irrespective of the patient's age, which they attributed to fasting/malnutrition. ${ }^{13}$ This fact highlights the importance of interpreting biochemical results in conjunction with the clinical scenario. As observed in the index patient, a critically ill neonate would have a lower-than-average fat intake leading to less chylomicron production, thus lower triglyceride levels in chyle than expected, which may still fail to meet the amended cut-off limit. Therefore, another approach to interpreting fluid biochemistry is to use 'ratios' for the diagnosis to compensate for any confounding factors. ${ }^{6-8}$ Suggested ratios for the diagnosis of chylothorax include fluid-to-serum triglyceride ratio $>1$, fluid-to-serum cholesterol ratio $<1$, fluid triglyceride-to-cholesterol ratio $>1$, which were demonstrated during the diagnostic workup in the index patient. On standing, chyle separates into three layers: a creamy uppermost layer with chylomicrons, a milky intermediate layer and a dependent layer with cellular elements; predominantly lymphocytes. ${ }^{14}$ Therefore, demonstrating low triglyceride levels in the infranatant of the centrifuged sample is another method to attribute the high fluid triglyceride levels to the chylomicrons that characteristically float due to their low density.

Given the similarities in the macroscopic appearance, pseudochylothorax, empyema and extravasated parenteral lipids administered via a central line are the other primary differential diagnoses in patients presenting with 'milky' pleural effusions. The onset of chylothorax is usually acute or subacute, whereas pseudo-chylothorax and empyema are insidious. Pseudochylothorax usually develops in long-standing pleural effusions due to cholesterol crystal formation without disturbance to the thoracic duct. ${ }^{6}$ Adding 1-2 mL of ethyl ether can clear the 'milky' appearance in pseudo-chylothorax but not in chylothorax, whereas in empyema, the turbidity is due to suspended pus cells, thus produces a clear supernatant following centrifugation. ${ }^{7}$ The characteristic findings of chylothorax, pseudo-chylothorax and empyema are compared in table $4 .^{6-8} 15-17$

During the biochemical analysis, the impact of high triglyceride on the analytical methods needs to be considered as triglyceride in the chylous fluid causes analytical interference by spectral interference, non-homogeneity of the sample and volume displacement effect. Spectral interferences may be alleviated by serial dilutions, analysis of the infranatant or using LipoClear (a liquid polymer reagent clearing lipaemia). Non-homogeneity and volume displacement may be lessened by centrifugation and using the infranatant with fewer chylomicrons for the analysis. Presence of lipids in the fluid results in spuriously high protein levels when using the sulfosalicylic acid method to analyse chylous fluid protein. 
Table 4 Comparison of characteristic findings in three 'milky' pleural effusions

\begin{tabular}{|c|c|c|c|c|c|}
\hline \multirow{2}{*}{ Test } & & \multirow[b]{2}{*}{ Chylothorax } & \multirow[b]{2}{*}{ Pseudo-chylothorax } & \multicolumn{2}{|l|}{ Empyema } \\
\hline & & & & Simple & Complicated \\
\hline \multirow[t]{3}{*}{ Macroscopy } & Appearance & & Opalescent white & & \\
\hline & Centrifugation & Forms a creamy upper layer & Remains uniform & \multicolumn{2}{|c|}{ Forms a clear supernatant } \\
\hline & Addition of $1 \mathrm{~mL}$ of ether & Milky appearance remains & Milky appearance disappears & \multicolumn{2}{|c|}{ Milky appearance remains } \\
\hline \multirow[t]{6}{*}{ Lipid analysis } & Triglyceride & $>1.24 \mathrm{mmol} / \mathrm{L}(110 \mathrm{mg} / \mathrm{dL})$ & $<0.56 \mathrm{mmol} / \mathrm{L}(50 \mathrm{mg} / \mathrm{dL})$ & \multicolumn{2}{|c|}{ Absent } \\
\hline & Cholesterol & $<5.17 \mathrm{mmol} / \mathrm{L}(200 \mathrm{mg} / \mathrm{dL})$ & $>5.17 \mathrm{mmolL}(200 \mathrm{mg} / \mathrm{dL})$ & \multicolumn{2}{|c|}{ May present if long-standing } \\
\hline & Fluid-to-serum triglyceride ratio & $>1.0$ & $<1.0$ & \multicolumn{2}{|c|}{-} \\
\hline & Fluid-to-serum cholesterol ratio & $<1.0$ & $>1.0$ & \multicolumn{2}{|l|}{-} \\
\hline & Fluid cholesterol/ triglyceride ratio & $<1.0$ & $>1.0$ & \multicolumn{2}{|l|}{-} \\
\hline & Lipoprotein electrophoresis & Chylomicrons present & No chylomicrons & \multicolumn{2}{|l|}{-} \\
\hline \multirow[t]{4}{*}{ Biochemistry } & Glucose & $2.7-11 \mathrm{mmol} / \mathrm{L}$ & $<2.2 \mathrm{mmol} / \mathrm{L}$ & $>2.2 \mathrm{mmol} / \mathrm{L}$ & $<2.2 \mathrm{mmol} / \mathrm{L}$ \\
\hline & Total protein & $20-30 \mathrm{~g} / \mathrm{L}$ & $<30 \mathrm{~g} / \mathrm{L}$ & \multicolumn{2}{|l|}{$>30 \mathrm{~g} / \mathrm{L}$} \\
\hline & $\mathrm{pH}$ & $7.4-7.8$ & $<7.35$ & $>7.2$ & $<7.2$ \\
\hline & LDH & $<2 / 3 \times$ UNL & Variable & \multicolumn{2}{|c|}{$>2 / 3 \times$ UNL $(>1000 \mathrm{IU} / \mathrm{L})$} \\
\hline \multirow[t]{5}{*}{ Microscopy } & Absolute cell count & $>1000$ cells/ $/ \mathrm{L}$ & Variable depending on underlying pathology & \multirow[t]{3}{*}{ No/ few pus cells } & $>1000$ cells $/ \mu \mathrm{L}$ \\
\hline & Lymphocytes & $>80 \%$ & & & $<10 \%$ \\
\hline & Polymorphs & $<20 \%$ & & & $>90 \%$ \\
\hline & Organisms & Absent & Organisms \pm & Absent & Organisms \pm \\
\hline & Cholesterol crystals & Absent & Present & Absent & Present if long-standing \\
\hline Culture & & No growth & Depends on the pathology & No growth & Bacterial growth+ \\
\hline
\end{tabular}

LDH, lactate dehydrogenase; UNL, upper normal limit (in the serum).

Congenital causes of neonatal chylothorax include congenital lymphatic malformations (pulmonary lymphangiomatosis, lymphangiectasia, thoracic duct atresia) and chylothoraxassociated syndromes (such as Down, Noonan, Turner, GorhamStout, X-linked myotubular myopathy). Although up to $50 \%$ of neonatal chylothorax may be associated with a genetic syndrome, diagnosing a defined syndrome may be difficult. ${ }^{14}$ Acquired causes of neonatal chylothorax include thoracic surgical interventions and perinatal trauma due to hyperexpansion/stretching of the chest wall during resuscitation or birth. ${ }^{618} 19$ Considering the clinical presentation, pleural effusion of traumatic chylothorax can have a latent period of 2-10 days, as observed in the index patient. In contrast, congenital chylothorax usually manifests antenatally as a space-occupying lesion restricting lung development, with $50 \%$ presenting with pleural effusion on day 1 of life. ${ }^{68}$

The initial management of chylothorax is aimed at patient stabilisation by draining the chylothorax to allow lung expansion, ventilatory support and replacement of fluid loss. Specific treatment includes medium-chain triglyceride (MCT) feeds and octreotide in the presence of continuous pleural fluid output. MCT is directly absorbed to portal circulation, bypassing lymphatics; thus, feeding MCT or keeping the patient nil-bymouth with total parenteral feeding can resolve $50 \%$ of the cases. ${ }^{8}$ In the event of failure to respond to the above measures, identifying the site of rupture in the thoracic duct by lymphangiography and direct ligation of the duct is the definitive surgical management. ${ }^{68}$ Despite available medical and surgical management options, neonatal chylothorax has a high mortality rate ranging between $20 \%$ and $60 \%$, especially when associated with other comorbidities. ${ }^{45}$ In congenital forms of neonatal chylothorax, high mortality rates are observed when associated with hydrops fetalis, whereas, in acquired forms of neonatal chylothorax, the prognosis is poor when associated with prematurity and infection as observed in the index patient. ${ }^{4}$ Further, the loss of lymphocytes and immunoglobulins in the chyle may have contributed to the worsening of the sepsis in the index patient, which led to her demise, among other contributory factors.

The index case highlights that the applicability of the amended definition for paediatric chylothorax depends on the minimal oral fat intake; thus, it may not alleviate the dilemma faced during the diagnosis of neonatal chylothorax and chylothorax in malnourished/non-orally fed patients irrespective of their age. Therefore, in scenarios with inconclusive fluid triglyceride levels, ratios calculated based on fluid and serum triglyceride and cholesterol values may be conveniently applied in place of triglyceride cut-off values for the tentative diagnosis of chylothorax.

\section{Learning points}

Although rare, chylothorax should be considered a primary differential diagnosis in perinatal pleural effusions.

- Applicability of triglyceride cut-off values in chylothorax depends on the minimal oral fat intake by the patient irrespective of age.

- In cases with inconclusive fluid triglyceride levels, fluid-toserum triglyceride and cholesterol 'ratios' can be applied for the chylothorax diagnosis.

Acknowledgements We thank Dr Indika Neluwa-Liyanage, Lecturer, Department of Biochemistry, Faculty of Medical Sciences, University of Sri Jayewardenepura, for his expertise and assistance in critically reviewing the manuscript.

Contributors UDS participated in the patient management by planning, conducting and critical interpretation of laboratory investigations, designed and wrote the initial draft of the manuscript. RR provided clinical care for the patient and critically reviewed the manuscript. BKTPD participated in the patient management by critical interpretation of laboratory investigations and critically reviewed the manuscript.

Funding The authors have not declared a specific grant for this research from any funding agency in the public, commercial or not-for-profit sectors.

Competing interests None declared. 
Patient consent for publication Obtained.

Provenance and peer review Not commissioned; externally peer reviewed.

Open access This is an open access article distributed in accordance with the Creative Commons Attribution Non Commercial (CC BY-NC 4.0) license, which permits others to distribute, remix, adapt, build upon this work non-commercially, and license their derivative works on different terms, provided the original work is properly cited and the use is non-commercial. See: http://creativecommons.org/ licenses/by-nc/4.0/.

\section{ORCID iD}

Udara Dilrukshi Senarathne http://orcid.org/0000-0003-2329-6871

\section{REFERENCES}

1 Downie L, Sasi A, Malhotra A. Congenital chylothorax: associations and neonatal outcomes. J Paediatr Child Health 2014:50:234-8.

2 Bialkowski A, Poets CF, Franz AR, et al. Congenital chylothorax: a prospective nationwide epidemiological study in Germany. Arch Dis Child Fetal Neonatal Ed 2015;100:F169-72.

3 Sze SWP, Ng PC, Lam HS. Life-Threatening hemolytic anemia after intrapleural instillation of OK-432 for treatment of congenital chylothorax. Neonatology 2016;110:303-6.

4 White MK, Bhat R, Greenough A. Neonatal Chylothoraces: a 10-year experience in a tertiary neonatal referral centre. Case Rep Pediatr 2019;2019:1-4.

5 Bagur Krishnamurthy M, Malhotra A. Congenital chylothorax: current perspectives and trends. Res Rep Neonatol 2017;7:53-63.
6 Tutor JD. Chylothorax in infants and children. Pediatrics 2014;133:722-33.

7 McGrath EE, Blades Z, Anderson PB. Chylothorax: aetiology, diagnosis and therapeutic options. Respir Med 2010;104:1-8.

8 Büttiker V, Fanconi S, Burger R. Chylothorax in children: guidelines for diagnosis and management. Chest 1999:116:682-7.

9 Hillerdal G. Chylothorax and pseudochylothorax. Eur Respir J 1997;10:1157-62.

10 Hooper C, Lee YCG, Maskell N, et al. Investigation of a unilateral pleural effusion in adults: British thoracic Society pleural disease guideline 2010. Thorax 2010;65 Suppl 2:ii4-17.

11 Staats BA, Ellefson RD, Budahn LL, et al. The lipoprotein profile of chylous and nonchylous pleural effusions. Mayo Clin Proc 1980;55:700-4.

12 van Straaten HL, Gerards LJ, Krediet TG. Chylothorax in the neonatal period. Eur J Pediatr 1993;152:2-5.

13 Maldonado F, Hawkins FJ, Daniels CE, et al. Pleural fluid characteristics of chylothorax. Mayo Clin Proc 2009;84:129-33.

14 Merrigan BA, Winter DC, O'Sullivan GC. Chylothorax. Br J Surg 1997;84:15-20.

15 Soto-Martinez M, Massie J. Chylothorax: diagnosis and management in children. Paediatr Respir Rev 2009;10:199-207.

16 Ahmed AEH, Yacoub TE. Empyema thoracis. Clin Med Insights Circ Respir Pulm Med 2010:4:CCRPM.S5066-8.

17 Agrawal V, Sahn SA. Lipid pleural effusions. Am J Med Sci 2008;335:16-20.

18 Dubin PJ, King IN, Gallagher PG. Congenital chylothorax. Curr Opin Pediatr 2000;12:505-9.

19 Rocha G, Fernandes P, Rocha P, et al. Pleural effusions in the neonate. Acta Paediatr 2006;95:791-8.

Copyright 2021 BMJ Publishing Group. All rights reserved. For permission to reuse any of this content visit https://www.bmi.com/company/products-services/rights-and-licensing/permissions/

BMJ Case Report Fellows may re-use this article for personal use and teaching without any further permission.

Become a Fellow of BMJ Case Reports today and you can:

- Submit as many cases as you like

Enjoy fast sympathetic peer review and rapid publication of accepted articles

- Access all the published articles

Re-use any of the published material for personal use and teaching without further permission

\section{Customer Service}

If you have any further queries about your subscription, please contact our customer services team on +44 (0) 2071111105 or via email at support@bmj.com.

Visit casereports.bmj.com for more articles like this and to become a Fellow 